\title{
The Life History and Cell Cycle of Kryptoperidinium foliaceum, A Dinoflagellate with Two Eukaryotic Nuclei
}

\author{
Rosa Isabel Figueroa ${ }^{a, 1}$, Isabel Bravo $^{b}$, Santiago Fraga ${ }^{b}$, Esther Garcés ${ }^{a}$, and Gisela Llaveria ${ }^{a}$ \\ ${ }^{a}$ Departament de Biologia Marina i Oceanografia, Institut de Ciències del Mar-CMIMA, CSIC, P. Marítim de la \\ Barceloneta, 37-49, E08003 Barcelona, Spain \\ ' Instituto Español de Oceanografía, Centro Oceanográfico de Vigo, Subida á Radio Faro, 50, \\ E36390 Vigo, Spain
}

Submitted July 8, 2008; Accepted December 7, 2008

Monitoring Editor: Saul Purton

\begin{abstract}
Kryptoperidinium foliaceum is a binucleate dinoflagellate that contains an endosymbiont nucleus of diatom origin. However, it is unknown whether the binucleate condition is permanent or not and how the diatom nucleus behaves during the life history processes. In this sense, it is also unknown if there is a sexual cycle or a resting stage during the life history of this species, two key aspects necessary to understand the life history strategy of this dinoflagellate. To answer these questions, life history and cell cycle studies were performed with the following results: (i) Kryptoperidinium foliaceum has a sexual cycle and in the dinoflagellate strains studied, the binucleate condition is permanent. Sexuality in the host was confirmed by the presence of fusing gamete pairs and planozygotes in clonal cultures (revealing homothallism), but signs of meiosis in the endosymbiont were not observed. The endosymbiont nucleus likely fuses first, because fusing gamete pairs were found to have two dinoflagellate nuclei but only one endosymbiont nucleus. After complete gamete fusion, the planozygotes had apparently normal endosymbiont and dinoflagellate nuclei. (ii) Asexual division studies using flow cytometry showed that the $S$ phase in the endosymbiont (diatom) nucleus starts 6-8 $\mathrm{h}$ later than in the host nucleus, but there was no evidence of mitosis in the former. (iii) Sexual and asexual cysts were formed in culture. Neither cysts from natural samples nor those formed in culture exhibited a dormancy period before germination.

(c) 2009 Elsevier GmbH. All rights reserved.
\end{abstract}

Key words: Kryptoperidinium foliaceum; binucleate; cell cycle; cysts; dinoflagellate; endosymbiont; life history; sexual reproduction.

\section{Introduction}

Eukaryotic mitochondria and plastids are unique in that they evolved from free-living prokaryotes through endosymbiosis (Bhattacharya et al. 2007). The endosymbiosis hypothesis (Margulis 1970;

${ }^{1}$ Corresponding author; fax +34932309555

e-mail figueroa@icm.csic.es (R.I. Figueroa).
Martin and Kowallik 1999), originally formulated to explain the origin of mitochondria and plastids, states that plastids most likely originated from a single primary endosymbiotic event between a eukaryotic host and a cyanobacterium, thereby giving rise to plants, green and red algae, and glaucophytes. On several occasions, these 
primary algae were themselves taken up by another eukaryote and permanently integrated in what is referred to as secondary endosymbioses. One algal group that contains a secondary plastid thought to have been derived from the red algal plastid lineage is the dinoflagellates. Their secondary plastid, called the peridinin plastid, is distinguished by the pigment peridinin and by three bounding membranes rather than the four common to most secondary plastids (see Falkowski et al. 2004; Yoon et al. 2005 for a review). However, other hypotheses suggest that the peridinin plastid evolved from a heterokont alga through a tertiary endosymbiosis (Bodył and Moszczyński 2006). Dinoflagellates are unique among eukaryotic algae in that they have taken the process of endosymbiosis one step further, since in several independent lineages the peridinin plastid has been replaced either with a successive secondary plastid or with a plastid from another secondary alga, resulting in tertiary plastids. Examples are the dinoflagellate groups of haptophyte (Karenia, Karlodinium, Takayama) (Yoon et al. 2002), green algal (Lepidodinium) (Watanabe et al. 1990), and diatom origin (Kryptoperidinium, Durinskia, Galeidinium, and Dinothrix as well as some species presently included in Peridinium [P. quinquecorne] and Gymnodinium [G. quadrilobatum]). The diatom endosymbiont is related to either centric ( $P$. quinquecorne) (Horiguchi and Takano 2006) or pennate (Kryptoperidinium) (Chesnick et al. 1996, 1997) groups. The tertiary endosymbiosis is more or less stable, depending on the dinoflagellate group, although knowledge of the symbiont-host system is limited, mainly restricted to genera such as Kryptoperidinium. An endosymbiosis is considered to be stable if there is genetic integration of the endosymbiont and host, meaning transfer of essential endosymbiont genes to the host nucleus and protein retargeting (Bhattacharya et al. 2007). For example, Dinophysis has long been considered to have a cryptophyte endosymbiont chloroplast, but the latter was very recently found to have been acquired through kleptoplastidy (Koike et al. 2005; Minnhagen and Janson 2006; Takishita et al. 2002).

The degree to which symbiosis has evolved differs depending on the particular genus and on the organelle. In some genera, such as Karenia, Alexandrium, and Karlodinium, chloroplast genes have been permanently transferred to the host nucleus (Hackett et al. 2004; Ishida and Green 2002; Patron et al. 2006). In Durinskia and Kryptoperidinium, mitochondrial genes of both host and endosymbiont are expressed (Imanian and Keeling 2007), but there is also a relict endosymbiont nucleus that may be in the process of being eliminated (Kempton et al. 2002). This suggests that Kryptoperidinium foliaceum is in an intermediate stage of endosymbiont reduction (Imanian et al. 2007).

Although chloroplast symbiosis is clearly stable in $K$. foliaceum-like dinoflagellates, there are conflicting data about the nature of the nuclear symbiotic relationship. While some studies point to an obligate association of the endosymbiont nucleus with its host, others suggest that the association is transient (Kempton et al. 2002; Wolny et al. 2004). However, most of the available data on endosymbiosis are derived from genetic studies, whereas the behavior of the endosymbiont-host system during the dinoflagellate life cycle remains poorly understood. These aspects were the focus of the present study.

Little is known about the life cycles of dinoflagellates with respect to tertiary endosymbiosis. Chesnick and Cox $(1987,1989)$ described gamete fusion and zygote formation in $D$. baltica, the only species of the group for which a sexual life cycle has been, at least partially, elucidated: during zygote formation, the dinokaryotic nuclei fuse first followed by plasmogamy of the symbionts; the endosymbiont nuclei fuse later, after migrating to a central position. It was suggested that these nuclei are products of meiosis, but since the isolated zygotes either died or ceased development under culture conditions, the sexual route could not be completely confirmed, nor has a cyst stage been described. The existence of fusing gamete pairs was also reported for $K$. foliaceum (named as Glenodinium foliaceum in BlanchardBabillot 1972), although neither progress of the fusion process nor a planozygote stage was observed. Therefore, two important questions related to the life cycle of the two nuclei-bearing species remain unanswered:

(i) Is there mitosis in the endosymbiont nucleus? Dinoflagellates are haploid eukaryotes with permanently condensed chromosomes (see Rizzo 1991 for review) whereas diatoms are diploid and chromatin condensation should precede mitosis. However, this latter process has never been seen in the group of twonuclei-bearing dinoflagellates and only a small condensation phase was depicted for D. baltica (Chesnick and Cox 1987, 1989); therefore, amitosis (division of the nucleus by means of constriction without the chromosome 
condensation typical of mitosis) has been proposed for both $D$. baltica (Tippit and Pickett-Heaps 1976) and K. foliaceum (Blanchard-Babillot 1972).

The DNA content of the endosymbiont nucleus of $K$. foliaceum ( $35 \mathrm{pg}$ ) is unusually large compared to the nuclei of its possible freeliving chromophyte relatives. A previous study showed that DNA content is relatively constant within a given strain but not within the species (Kite et al. 1988). To study the stability and a possible cell cycle of the nuclear endosymbiont (DNA synthesis), the host and endosymbiont were analyzed using flow cytometry and observed by light and electron microscopy.

(ii) Is there efficient sexuality (i.e., a viable planozygote) during the life cycle of $K$. foliaceum? If so, is there sexuality in both the endosymbiont and the dinoflagellate? Since diatoms are diplonts, chromatin condensation and chromosome reduction should accompany meiosis in the endosymbiont nucleus. To verify this process, the nuclei of culture-formed planozygotes were stained and then observed by fluorescence microscopy.

\section{Results}

\section{Morphology}

\section{Vegetative Motile Stage}

The study of tabulation in $K$. foliaceum is difficult such that most of the descriptions found in the literature are not very accurate and perhaps represent more than one species. To avoid possible misinterpretations in identifying the organism, the morphology of the strains used in this study is as follows: The plate formula of our strains is $3^{\prime}, 2 \mathrm{a}, 7^{\prime \prime}, 4 \mathrm{c}, ? \mathrm{~s}, 5^{\prime \prime \prime}, 2^{\prime \prime \prime \prime}$ (Fig. 1a, b). The cells were extremely flattened dorsoventrally so that the plates were observed on their ventral or dorsal sides. The sutures of some plates were on the edge but other plates were folded, with a ventral side and a dorsal side. Plates having two sides were: apicals $2^{\prime}$ and $3^{\prime}$, precingulars $2^{\prime \prime}$ with only a small dorsal side and $6^{\prime \prime}$, postcingulars $2^{\prime \prime \prime}$ and $5^{\prime \prime \prime}$, the last one with a small dorsal side, and the two antapicals. The shape of three plates was very peculiar. Sa was quite large with an indentation in the epitheca and thus easily confused with a precingular plate. Plate $7^{\prime \prime}$ was L-shaped, very narrow, much thicker than the other plates of the
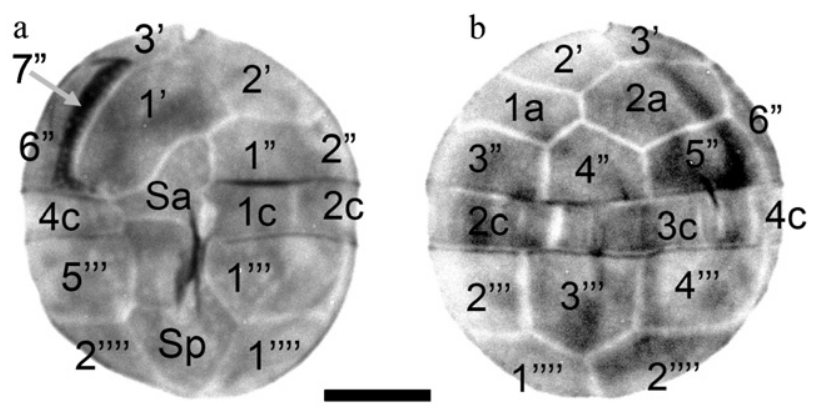

Figure 1. Kryptoperidinium foliaceum (strain Baiona B9), as observed by light microscopy. Ventral (a) and dorsal (b) views. Scale bar: $10 \mu \mathrm{m}$.

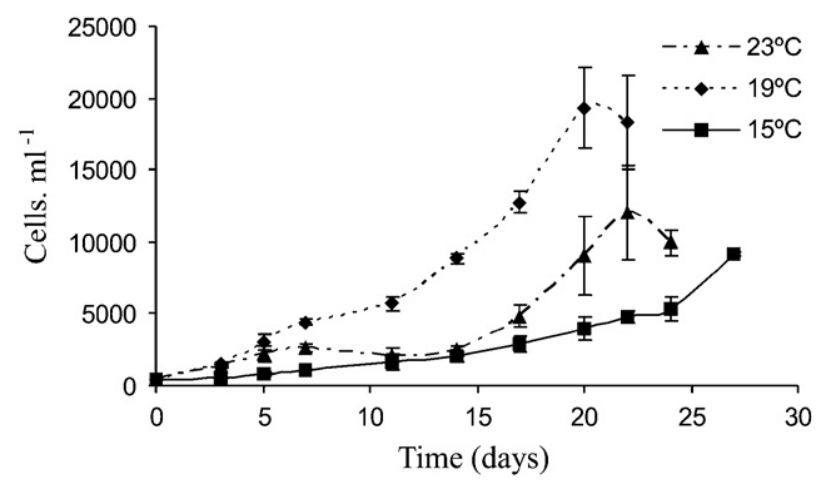

Figure 2. Growth of $K$. foliaceum at different temperatures. Data points are averages and vertical bars are standard errors/SD of the mean.

theca, and formed the right edge of the epitheca (Fig. 1a). The first apical plate $1^{\prime}$ was very large and kidney-shaped, with the concavity formed by Sa. Our strains are characterized by a conspicuous red stigma centered in the area of their flagellar pores.

\section{Non-Motile Stage (Cysts)}

The non-motile benthic stage (cyst) $(18-35 \mu \mathrm{m}$ long, $14-35 \mu \mathrm{m}$ wide) is round, flattened, and has one or more reddish spot(s) (Figs 7a, 8d and 9a).

\section{Growth Rate in Culture}

$K$. foliaceum had the highest division rates at the two highest temperatures tested (Fig. 2): at $19^{\circ} \mathrm{C}$, $0.24 \pm 0.02$ divisions day $^{-1}$, and at $23^{\circ} \mathrm{C}$, $0.23 \pm 0.01$ divisions day $^{-1}$. The division rate was significantly lower $\left(0.18 \pm 0.01\right.$ divisions day ${ }^{-1}$, ANOVA $p<0.05)$ at $15^{\circ} \mathrm{C}$. 


\section{K. foliaceum DNA Content and Cell Cycle by Flow Cytometry}

The haploid DNA content of synchronized $K$. foliaceum cultures was comparable to the DNA content of other dinoflagellates, particularly Alexandrium minutum (Fig. 3a), and was estimated to be $\sim 30 \mathrm{pg}$ per cell, based on a relative comparison with the DNA content of that species. However, depending on the sampling time, two haploid DNA contents were found, one of which corresponded to the $K$. foliaceum endosymbiont (Fig. 3b-d). Also, cell-cycle analyses showed two $S$ phases and two peaks of G2M cells (Fig. 3e), suggesting that the endosymbiont nucleus enters $\mathrm{S}$ phase $6-8 \mathrm{~h}$ later than the host nucleus.

\section{K. foliaceum Life Cycle}

The dominant life-cycle stage of $K$. foliaceum is a motile form with one longitudinal flagellum (Fig. 4a, b) and a typical dinoflagellate nucleus (dinokaryon) that is almost spherical and with permanently condensed chromosomes. There is also a thin and elongated endosymbiontic nucleus, in which the chromosomes are not distinguishable and sometimes this nucleus appear to be double branched (Fig. 4c, d). At some stages of development, there seems to be a small area connecting the two nuclei, as shown in Figure 4c.

Large differences in cell size, mainly in sexually induced cultures, were recorded (Fig. 4e). Small cells, some only $13 \mu \mathrm{m}$ in length, were stained to confirm that they contained dinokaryon and endosymbiont nuclei (Fig. 4f). The relative percentages of cells in each size fraction and the changes of the population size over time were determined by observing the cells in a Coulter counter. Table 1 shows the average increase in cell size over time. At the beginning of the exponential phase of growth, two size groups were identified but the size distribution became unimodal in later samplings, although with a larger standard deviation and a shift to larger cells (Table 1). The sizes of the cells during the different life-cycle stages were followed using an inverted light microscope (Table 2).

\section{Asexual Cycle}

Cell division takes place in both the motile and non-motile states (Fig. 5). In the motile state, division results in the formation of two motile cells. As shown in Figure $5 \mathrm{a}$ and $\mathrm{b}$, division occurred simultaneously and the dinokaryon and the endosymbiont nuclei acquired a similar bi-lobed shape (Fig. 5b). Non-motile cysts were abundant in clonal cultures and also underwent division (Fig. $5 c-e)$. The multiple rounds of division in some cases yielded up to 6 cells, which were consecutively released in $<24-48 \mathrm{~h}$ (Fig. 5f).

\section{Sexual Cycle}

Sexuality (fusing gamete pairs and planozygotes) was observed in clonal strains (reflecting homothallism). Fusing gamete pairs (Fig. 6a, b) were commonly detected in exponentially growing cultures. The gametes attached through the sulcal region at different angles of their respective cingula, ranging from a perpendicular (Fig. 6a) to an almost parallel orientation (Fig. 6b), and were of very different sizes (Table 2). In the fusing gamete pairs studied, the endosymbiont nuclei were in the process of fusion (Fig. 6c) or had already fused (Fig. 6d), whereas the dinoflagellate nuclei remained separated (Fig. 6c, d). Planozygotes were recognizable by the presence of two longitudinal flagella (Fig. 6e, f) and by their large size (Table 2). The endosymbiont nucleus of the planozygotes was spherical in shape, whereas the dinoflagellate nucleus was more elongated and larger than in the vegetative stages (Fig. $6 \mathrm{~g}$, h). The cysts were irregularly shaped, with a welldefined double wall and a large reddish spot (Fig. 7a). Some cysts had one dinokaryon and one endosymbiont nucleus (Fig. 7b), and liberated one cell, with one or two longitudinal flagella (Fig. 7c). Therefore, this cyst morphology matched both sexual and asexual cysts. Other cysts contained multiple cells (Fig. 7d) with up to four dinokaryon and four endosymbiont nuclei (Fig. 7e, f).

The sexual stages were also identified by scanning electron microscopy, which showed fusing gametes attached at different angles through the sulcal region, although their individual morphology was indistinguishable from that of the vegetative stage (hologamy) (Fig. 8a). Planozygotes were identified by the presence of two longitudinal flagella (Fig. 8b, c). The morphology of the cysts was highly variable. Some exhibited the morphological characteristics of vegetative stages, i.e., sulcal and cingular regions, whereas others were flattened and lacked any vegetative attributes (Fig. 8d).

\section{Field Study}

Sediment samples contained $3.3 \pm 0.6$ cysts of K. foliaceum per $\mathrm{ml}$ of wet sediment (Fig. 9a, b). 

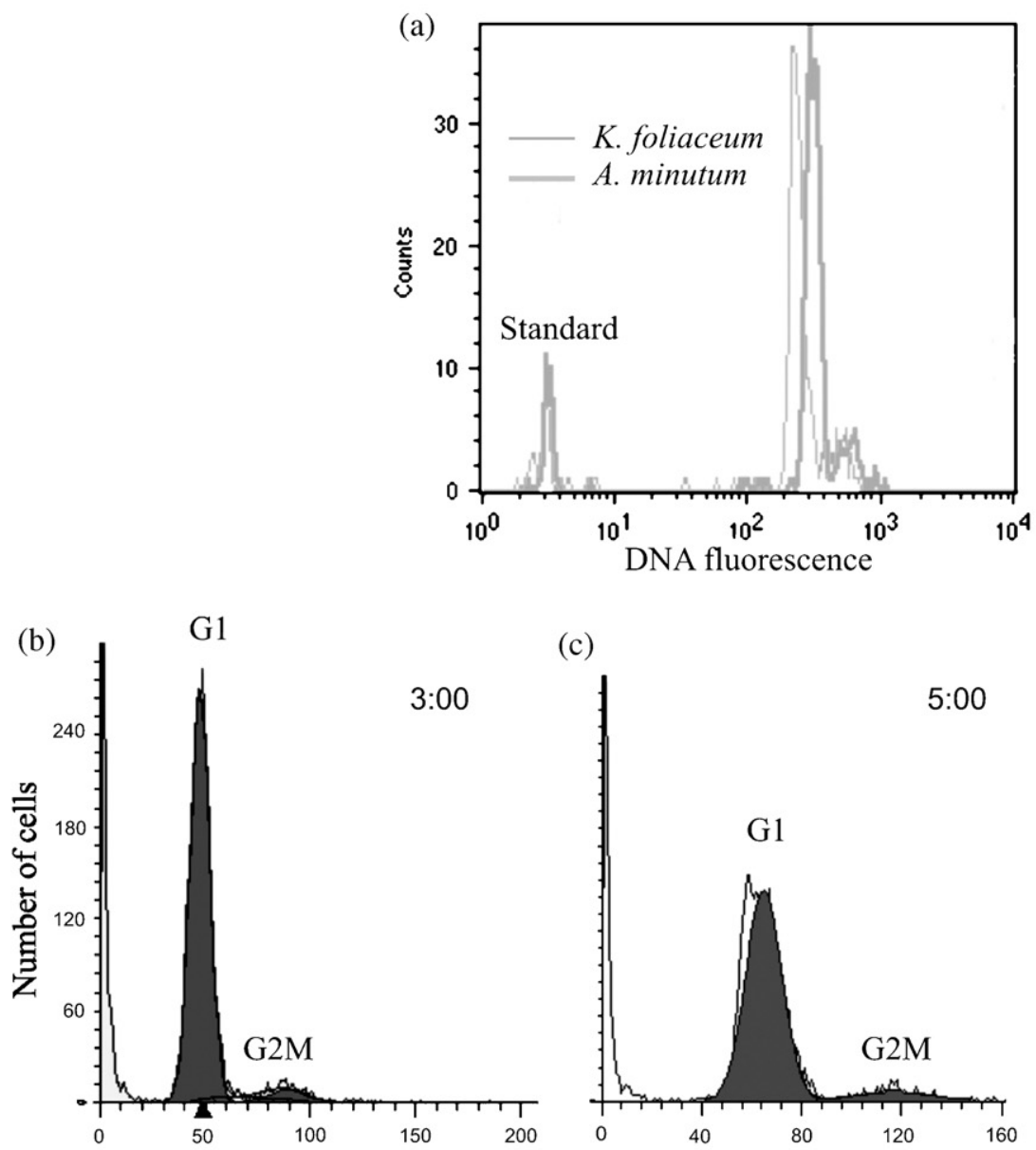

(c)

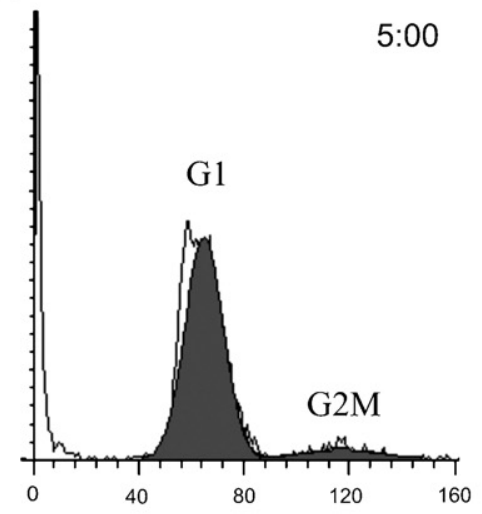

(d)

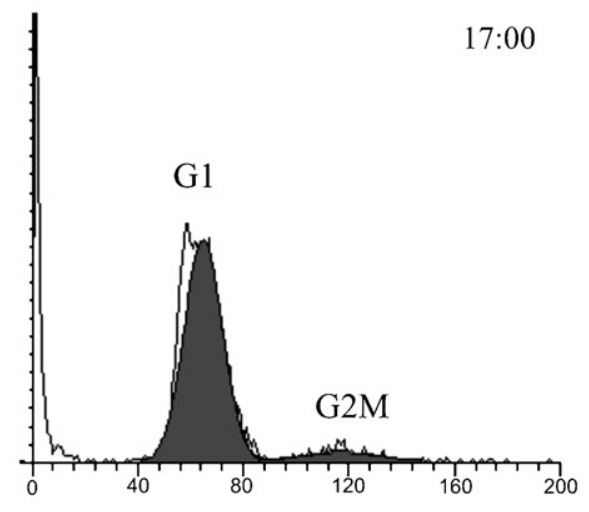

DNA fluorescence (FL2A)

(e)

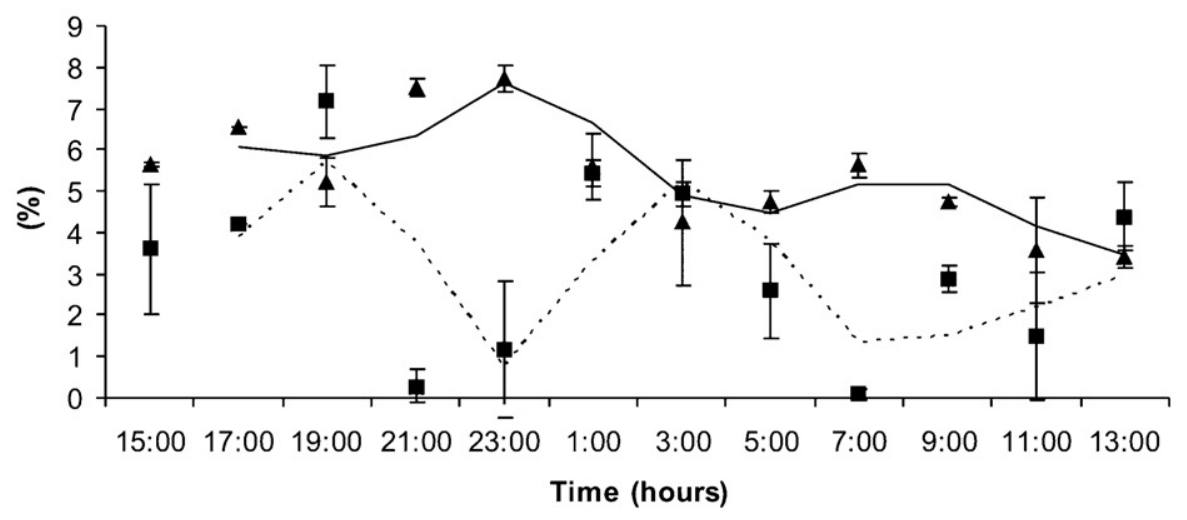

Figure 3. (a) Flow cytometry chart comparing the haploid DNA contents of $K$. foliaceum (thin line) and Alexandrium minutum (thick line). (b-d) Flow histograms of samples at different phases of the cell cycle. Dark and white areas are shown when the adjustment of the MODFIT program is better considering the presence of two haplo-diploid cycles (dark for the dinoflagellate nucleus and white for the endosymbiont nucleus). (e) Percentages of cells in S (squares) and G2/M (triangles) phases during a diel cell cycle. Data points are averages and vertical bars are standard errors/SD of the mean. The black bar represents the dark period of the diel cycle. The running mean indicates the expected values when the average value of the variable in a specific number of previous periods is considered. 

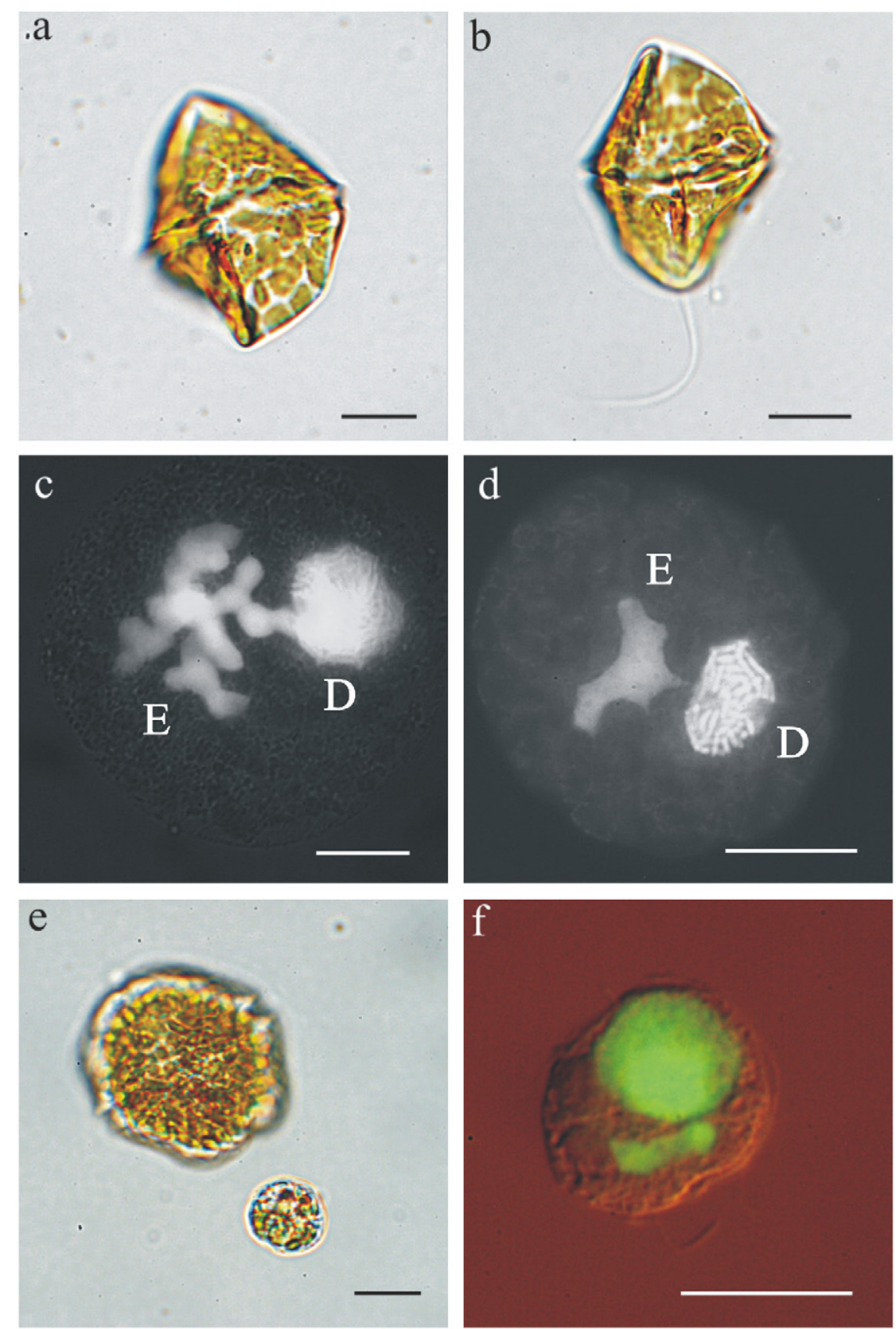

Figure 4. Vegetative stages of $K$. foliaceum (strain Baiona B9). External appearance (a, b) and nuclear morphology $(\mathbf{c}, \mathbf{d})$ of vegetative stages, $\mathrm{D}$ is showing the dinokaryon and $\mathrm{E}$ the endosymbiont nucleus; (e) comparison of sizes among culture cells; (f) nuclear morphology of the smaller cell shown in (e). Scale bars: $10 \mu \mathrm{m}$.

Whereas all of the cysts seemed to be unicellular with respect to their external appearance (Fig. 9a, b), nuclear staining consistently revealed two dinokaryon and two endosymbiont nuclei (Fig. 9c). All germlings studied presented one longitudinal flagellum (Fig. 9d) and one dinokaryon and one endosymbiont nucleus (Fig. 9e), although in some germlings the shape of the endosymbiont nucleus was similar to that observed in planozygotes from cultures (Fig. 9f). Cysts needed 1-2 days to germinate, with $100 \%$ germination frequency and $100 \%$ surviving germlings. 
Table 1. Volumes of cells, as determined using a Coulter counter, at different times of the growth curve.

\begin{tabular}{|c|c|c|c|c|c|c|c|c|c|}
\hline \multicolumn{2}{|c|}{ Growth (cell ml ${ }^{-1}$ ) } & \multicolumn{4}{|c|}{ Volume $\left(\mu \mathrm{m}^{3} \mathrm{ml}^{-1} \mu \mathrm{m}^{-1}\right)$} & \multicolumn{4}{|c|}{ Number of cells (\%) } \\
\hline Average & SD & $\begin{array}{l}\text { Group } 1 \\
\text { average }\end{array}$ & SD & $\begin{array}{l}\text { Group } 2 \\
\text { average }\end{array}$ & SD & $\begin{array}{l}\text { Group } 1 \\
\text { average }\end{array}$ & SD & $\begin{array}{l}\text { Group } 2 \\
\text { average }\end{array}$ & SD \\
\hline 1429 & 208 & 14 & 2.0 & 21 & 2.2 & 74 & 6.7 & 26 & 6.7 \\
\hline 2146 & 197 & 14 & 2.0 & 21 & 2.6 & 55 & 19.0 & 45 & 19.0 \\
\hline 5044 & 1527 & 14 & 2.1 & 22 & 2.7 & 65 & 0.5 & 35 & 0.5 \\
\hline 8700 & 890 & 16 & 4.5 & - & - & - & - & - & - \\
\hline 12,945 & 1727 & 18 & 5.5 & - & - & - & - & - & - \\
\hline 16,583 & 527 & 19 & 5.9 & - & - & - & - & - & - \\
\hline
\end{tabular}

Two modes of size (groups 1 and 2) were observed at the beginning of the exponential phase.

Table 2. Sizes of Kryptoperidinium foliaceum life-cycle stages $(n \geqslant 10)$ as determined by optical microscopy.

\begin{tabular}{lllll}
\hline Life-cycle stage & Length range $(\mu \mathrm{m})$ & Width range $(\mu \mathrm{m})$ & $\begin{array}{l}\text { Length }(\mu \mathrm{m}) \\
\text { (average } \pm \text { SD) }\end{array}$ & $\begin{array}{l}\text { Width }(\mu \mathrm{m}) \\
\text { (average } \pm S D)\end{array}$ \\
\hline Vegetative cells & $13-38$ & $10-30$ & $26 \pm 8$ & $22 \pm 7$ \\
Gametes & $14-23$ & $12-23$ & $17 \pm 4$ & $16 \pm 4$ \\
Planozygotes & $34-45$ & $31-38$ & $40 \pm 4$ & $33 \pm 4$ \\
Cysts & $18-35$ & $13-33$ & $29 \pm \pm 5$ & $26 \pm 4$ \\
Germlings & $31-33$ & $26-33$ & $32 \pm 2$ & $28 \pm 4$ \\
\hline
\end{tabular}

\section{Discussion}

Our results can be summarized in three main points; (i) in the studied strains the binucleate condition is permanent, (ii) evidence of neither mitosis nor meiosis (i.e., chromosomes condensation) was found in the endosymbiont nucleus, (iii) flow cytometry analyses suggest the existence of an S-phase in the endosymbiont nucleus.

Flow cytometric analyses indicated that the dinoflagellate nucleus contains around $30 \mathrm{pg}$ DNA/cell, whereas relatively minor amounts were measured in the endosymbiont nucleus. These estimates were based on a comparison with the DNA content of the dinoflagellate species Alexandrium minutum, whose DNA content was previously shown to be almost identical to that of our $K$. foliaceum strain (Figueroa et al. 2007). Our results were obtained by a different methodology than Kite et al. (1988), which may explain why these authors reported higher DNA content values for $K$. foliaceum than determined in this study.

The size of the endosymbiont nucleus was observed to be variable depending on culture growth conditions, since very small cells with noticeable smaller endosymbiont nucleus (Fig. 4) mainly occurred in our study after sexual induction in nutrient-deficient medium or in early phases of the growth curve, during which two size groups were identified using a Coulter counter. This method allowed us to corroborate the large differences in sizes observed by light microscopy.

A variable endosymbiont DNA content among different strains was reported by Kempton et al. (2002). These authors found that $K$. foliaceum may actually comprise two different but similar species, since two morphologically and genetically distinct groups were identified. Although we were not able to confirm the original description of Paulsen, the peculiar $7^{\prime \prime}$ was not included in previous descriptions of the species (Biecheler 1952; Lebour 1925; Lindemann 1924) and it was not until recently that plates of different strains were photographically described (Kempton et al. 2002). Our strains are similar to strains CCAP 1116/3 and CSIRO 291, based on figure $1 C$ and D in Kempton et al. (2002), but different from UTEX LB 1688, CCMP 1326 and their South Carolina isolates, as shown in figure $1 A$ and $B$, and $E$, in that report. Although the strains of this group were all binucleated, strains with or without an endosymbiont nucleus were described in the other group, formed by UTEX LB 1688 and CCMP 1326 and the South Carolina and Florida isolates (Kempton et al. 2002). The presence of an eyespot seems to be a variable feature of 

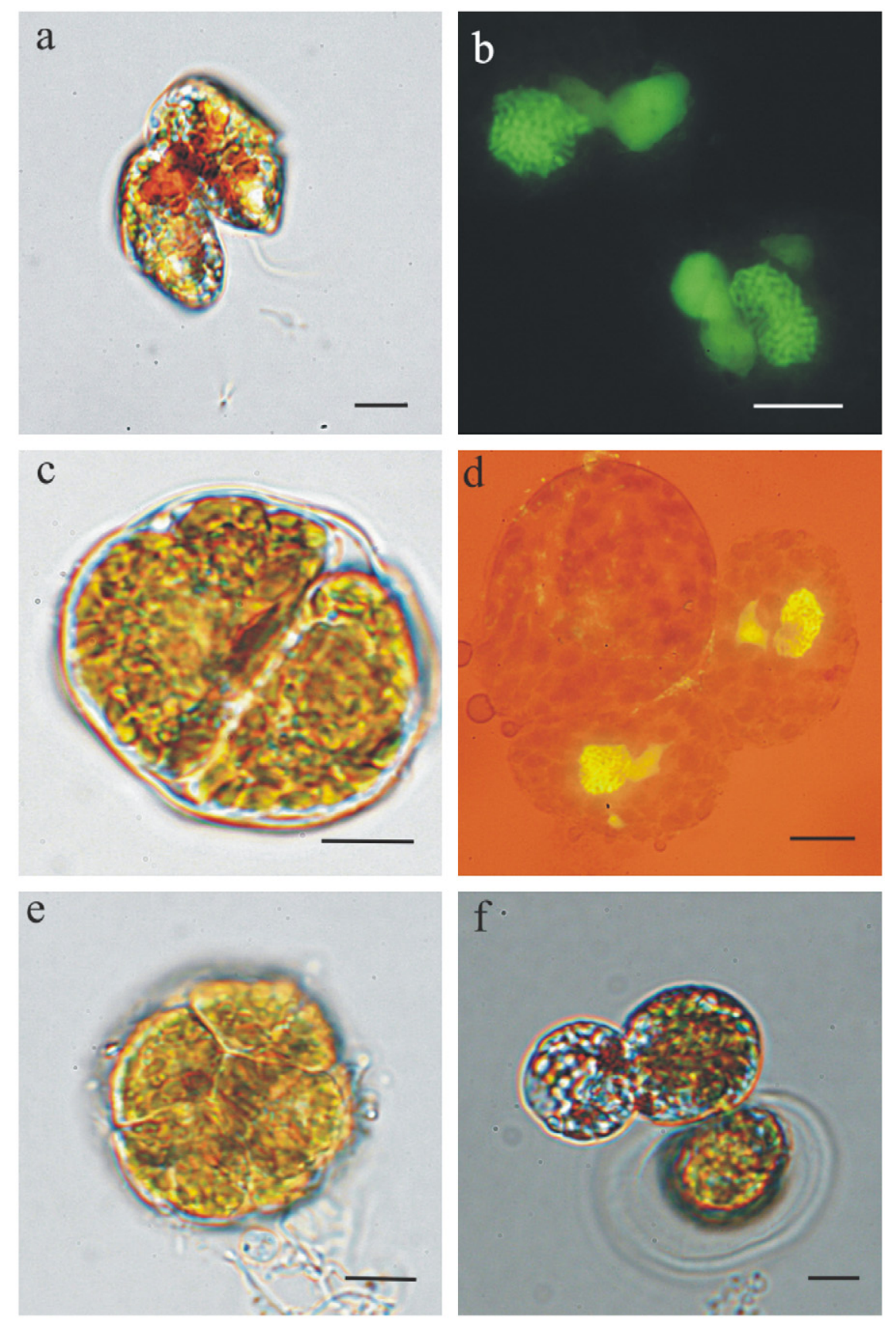

Figure 5. Dividing stages of $K$. foliaceum (strain Baiona A3). External morphology (a) and nuclear development (b) of a mobile stage in division, showing a completed mitosis. (c-f) Non-mobile dividing stages. Outer morphology (c) and nuclei (d) of a two-cell dividing cyst. Six-cell dividing cyst (e) and progressive germination (f). Scale bars: $10 \mu \mathrm{m}$.

Kryptoperidinium, as it was not observed in two (UTEX LB 1688 and CCMP 1326) of the four strains studied by Kempton et al. (2002). This variability is supported not only by the fact that not all the strains have an eyespot, but also because strain UTEX LB 1688, used by Dodge and
Crawford (1969) to describe the eyespot, was later claimed by Kempton et al. (2002) to lack one. Although we cannot rule out the possibility of a cryptic species within the genus, these findings, when considered together with our results on the variability in the size of the endosymbiont nucleus, 

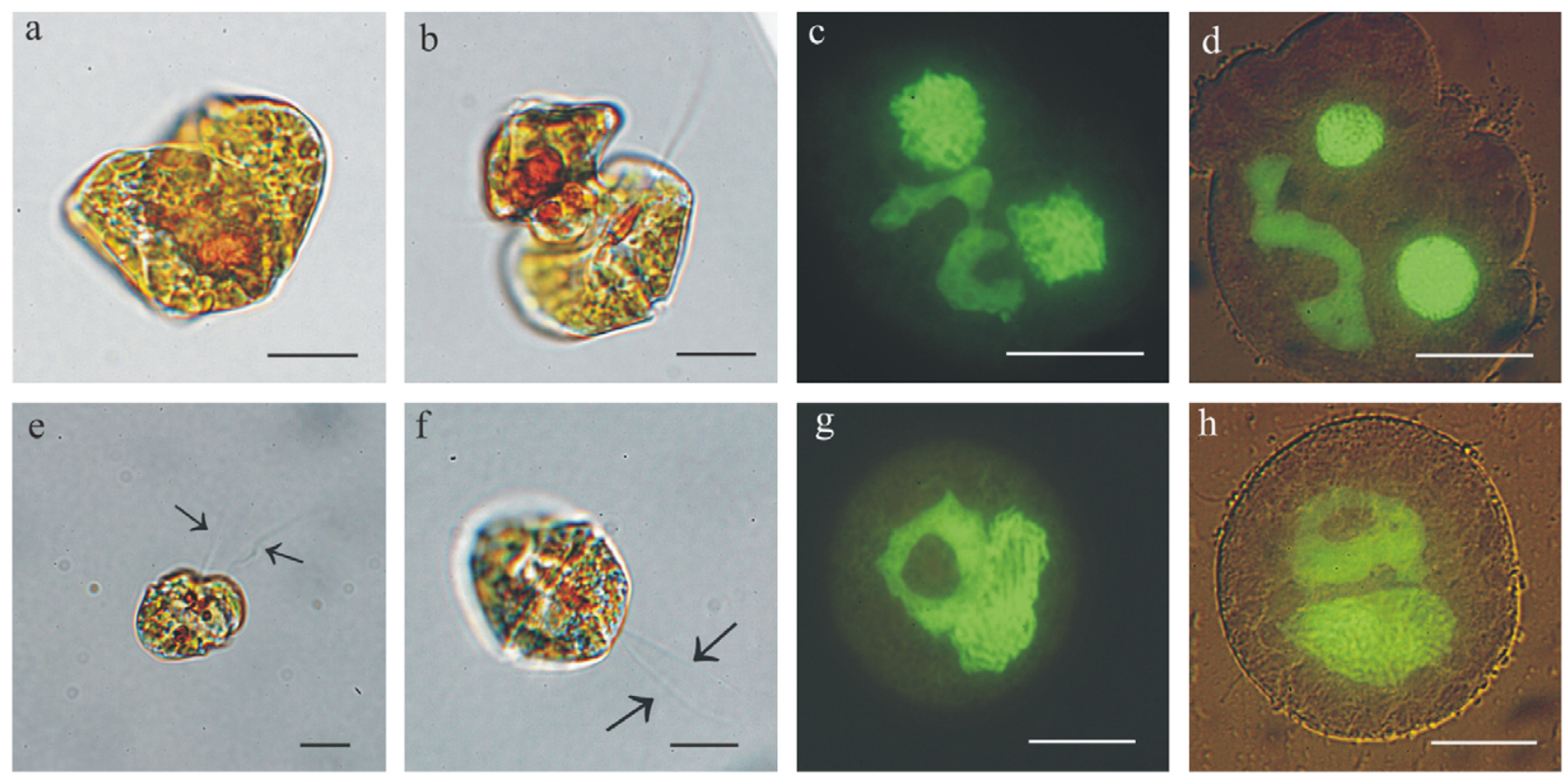

Figure 6. Sexual cycle of $K$. foliaceum (strain Baiona B9). Isogamous (a) and anisogamous (b) fusing gamete pairs. (c, d) Nuclear morphologies of fusing gamete pairs. (e, f) Planozygote external morphologies, showing the two longitudinal flagella (arrows). (g, h) Nuclear morphologies of planozygotes. Scale bar: $10 \mu \mathrm{m}$.

may suggest that gene transfer from the diatom to the dinoflagellate has already been accomplished and that the endosymbiont nucleus is no longer functional and in the process of being evolutionarily discarded (Bhattacharya et al. 2007).

Other observations support the conclusion that mitosis and meiosis are lacking in the endosymbiont nucleus. As in $D$. baltica (Tippit and PickettHeaps 1976) and $K$. foliaceum (Blanchard-Babillot 1972), no chromatin condensation or mitotic spindle was observed in the endosymbiont nucleus, suggesting that it does not undergo mitosis, although there may be a phase of DNA synthesis ( $\mathrm{S}$ phase) albeit delayed by $6-8 \mathrm{~h}$ relative to the dinoflagellate nucleus. A sexual process in the endosymbiont would imply endosymbiont meiosis simultaneous with dinoflagellate mitosis yielding haploid gametes. This possibility cannot be excluded because very small cells contained very small endosymbiont nuclei; nonetheless, there was no evidence of meiosis, since neither chromatin condensation nor chromosome segregation occurred. The complete sequence of endosymbiont fusion was described by Chesnick and Cox in their study of $D$. baltica (1989). However, our results suggest that, if endosymbiont fusion indeed takes place, then it must be at a very early stage of gamete fusion, prior to dinokaryon fusion and thus opposite to the sequence reported in $D$. baltica (Chesnick and Cox 1989). The lack of meiosis in the endosymbiont may be compatible with the typical sexual behavior of diatoms, since sexuality in these organisms is much less frequent than in dinoflagellates and usually only occurs about once a year, when there has been a critical reduction in size such that it is necessary to restore the normal cellular dimensions (see, for example, the revision of Lewis (1984)).

Among the organisms with an endosymbiontlike origin, those most related to $K$. foliaceum are $D$. baltica and G. rugatum (Horiguchi and Takano 2006). However, the morphology and life cycle (a dominant non-motile phase and a brief motile phase) of $G$. rugatum are completely different from those of other such species (Tamura et al. 2005). It is still unknown whether there is sexuality in the life cycle of these two-nuclei-bearing organisms. As mentioned above, Chesnick and Cox (1987) reported signs of sexuality in $D$. baltica, such as gamete fusion and zygote formation; however, as the viability of the zygotes was not determined, the existence of a sexual cycle could not be established. We observed planozygote encystment in $K$. foliaceum, thus confirming the existence of an effective sexual route in this strain.

Sexual reproduction is widespread among eukaryotes (Bell 1982), although it entails several 

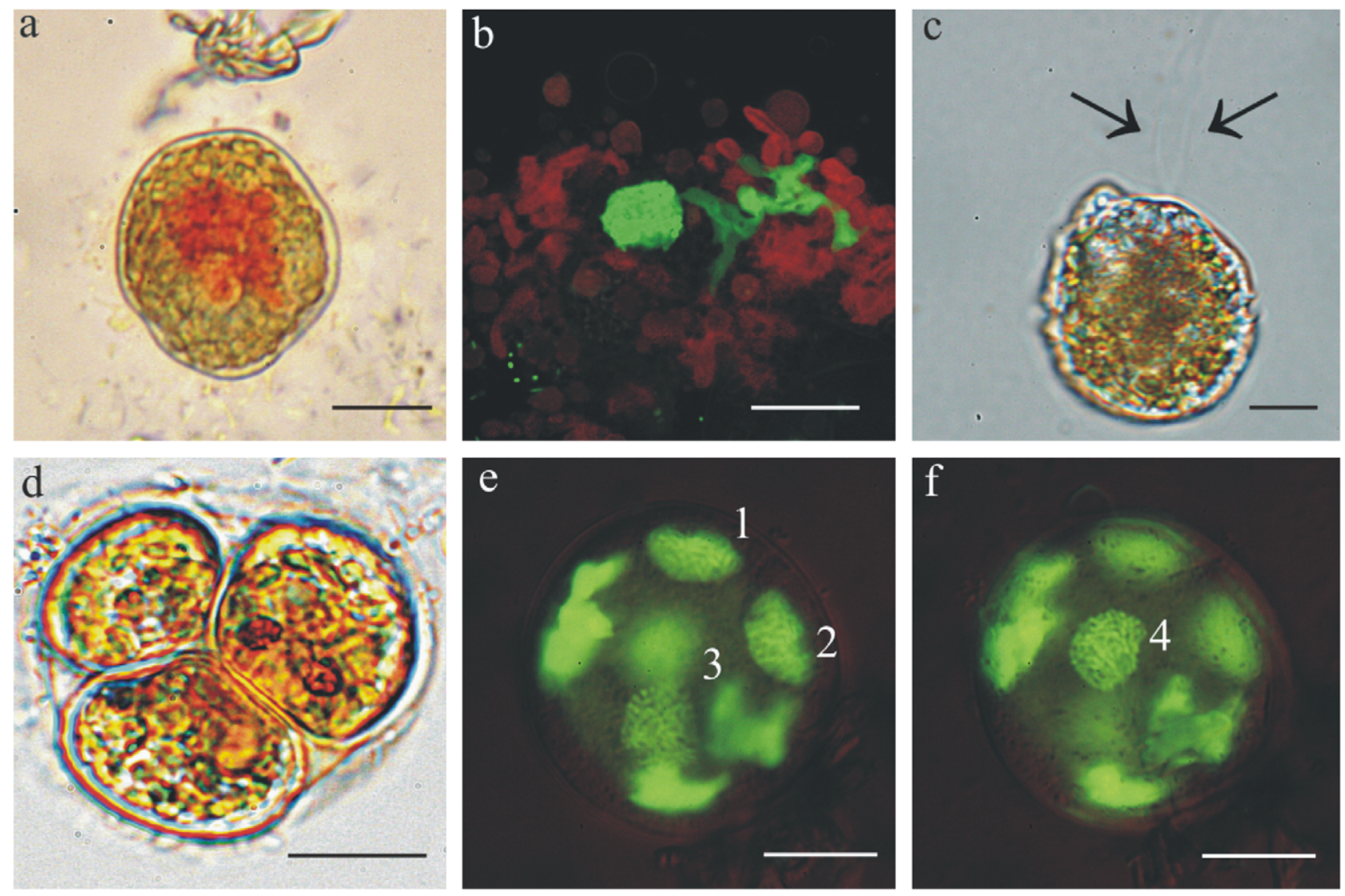

Figure 7. Encystment and germination of a culture cyst (strain Baiona A3). External morphology (a) and nuclei (b) of a culture cyst; (c) germling showing the two longitudinal flagella. Outer morphology (d) of a cyst containing four endosymbiont and four dinoflagellate nuclei (e, f). Scale bars: $10 \mu \mathrm{m}$.

costs that are avoided in asexual reproduction, for example, the need to find a mate. Conversely, in environments where perturbations are common, sexual recombination confers several benefits as it provides new genotypes that allow the population to adapt to the changing conditions (Hamilton 1980; Lively 1989) and to restore damaged DNA through recombinational repair (Bernstein 1983). This line of reasoning is consistent with the role of a sexual route in the life cycle of $K$. foliaceum, an organism that resides in shallow estuaries, that are highly and rapidly variable systems due to the strong effects of tides and river flow on their hydrological structure (Trigueros and Orive 2000). These habitats are common for other phylogenetically related species, such as $G$. quadrilobatum (Horiguchi and Pienaar 1994), D. capensis (Pienaar et al. 2007), and $P$. quinquecorne (unpublished data), and may explain homothallism as the mating-type system of $K$. foliaceum. In homothallism, sexual zygotes can be produced by selffertilization, i.e., by the fusion of genetically identical gametes. This ability makes sex energetically cheaper and facilitates more frequent sexual events within a population, because individuals do not lose energy in finding a partner with a compatible mating type. However, since homothallism implies the recombination of identical genotypes, the ability of sexual recombination to produce new genotypes is lost. Nonetheless, evidence for the advantages of sexual recombination comes from recent work showing that the fitness effects of sex in homothallic systems are not the result of recombination but rather are due to the fact that sex promotes the accumulation of fewer deleterious mutations (Bruggeman et al. 2003) and breaks up genetic association among loci (linkage disequilibria) (Otto 2003). In addition, if sexuality enables a resting stage, it provides other benefits, such as survival during unfavorable conditions, species dispersal, reproduction, and regulated seasonal succession (Anderson and Rengefors 2006; Anderson and Wall 1978; Anderson et al. 1984; Rengefors and Anderson 1998; 


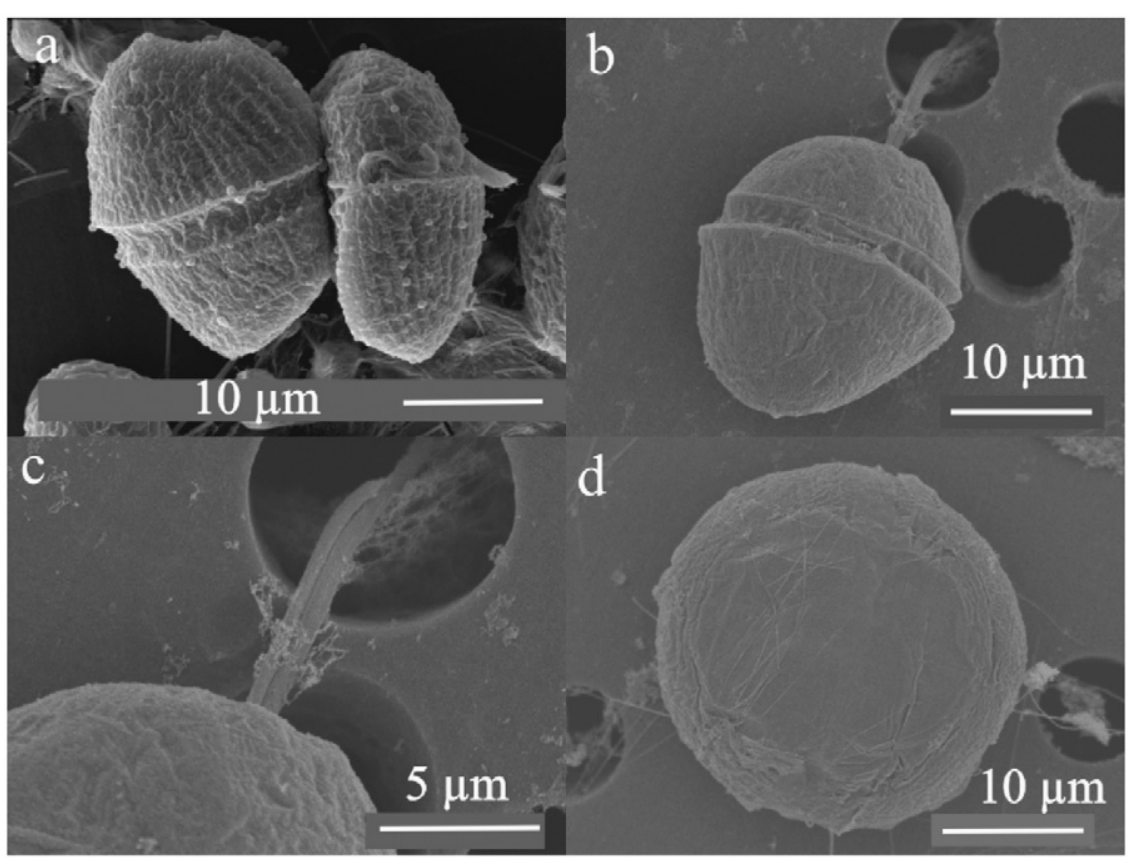

Figure 8. Scanning electron micrographs of the sexual stages of $K$. foliaceum (strain B1). (a) Fusing gamete pairs; (b, c) longitudinally biflagellated planozygote. Resting stage showing no vegetative attributes (d).

Wall 1971). Although not previously reported for $K$. foliaceum, we were able to document the formation of cysts in culture and in natural samples.

Two factors are important regarding sexual cyst formation in a given species; the sexual or asexual nature of the cysts and the dormancy period. $K$. foliaceum produced sexual and asexual cysts with identical external morphologies. It is thought that maintenance of the haplo-diplontic life cycle is advantageous when the environment offers two different ecological niches, each of which can be occupied by one of the two stages (Stebbins and Hill 1980; Steidinger and Garcés 2006). This becomes irrelevant when there is no relation between morphology and ploidy and a given morphology (the cyst) can occur in different ploidy levels (Lubchenco and Cubit 1980). However, this system can be maintained under conditions that favor short-lived individuals and thus promotes the selection of two short phases rather than a single long phase within a cycle (Richerd et al. 1993). Similarly, the requisite period of dormancy is 1-2 days, which is much shorter than that recorded for several other dinoflagellates. For example, in Alexandrium species, the dormancy period ranges from 1 to 12 months (Anderson 1980; Dale et al. 1978; Figueroa et al. 2006; Montresor and Marino 1996; Pérez et al. 1998; Walker and Steidinger 1979). By contrast, the cysts of Gymnodinium catenatum Graham germinate within 2 weeks or less (Bravo and Anderson 1994), and Peridinium gatunense Nygaard cysts excyst within $12 \mathrm{~h}$ after formation (Pfiester 1977). Similar to what we observed, these short time intervals do not provide a true dormancy condition. The length of the dormancy period is a factor that strongly determines the bloom pattern of a species. Long dormancy periods are related to long-term survival and seasonal successions because the organism is thus able to remain dormant in bottom sediments during temperature extremes, with seasonal germination inoculating vegetative cells into the water column only when the temperature and light conditions are suitable for growth (Anderson 1997). A short dormancy period indicates rapid cycling between benthic and planktonic stages (Hallegraeff et al. 1998), which may be crucial for survival when short-term variability has a much greater impact than the seasonal transition. This is consistent with the usual conditions of the $K$. foliaceum natural habitat. Thus, the life cycle described here serves as a clear model of adaptation to a challenging environment, such as an estuary, where the effect of diurnal or semi-diurnal tides plays a major role in controlling the main hydrological parameters and hence, the intensity, distribution, and species composition of blooms. 




Figure 9. Wild cysts and germination. External morphologies (a, b) and nuclear staining (c) reveals two endosymbiont and two dinoflagellate nuclei in natural cysts. (d) One of the cells resulting from cyst germination is shown; staining of the germling nuclei $(\mathbf{e}, \mathbf{f})$, with evidence of division in the endosymbiontic nucleus (f).

\section{Methods}

Culture isolation: Kryptoperidinium foliaceum was isolated from a recurrent bloom in the estuary of Miñor River (NW Spain). The bloom occurs during the summer months along the estuarine front, which is located, depending on the tides, from the mouth to a few $\mathrm{km}$ up-river. A strong saline vertical gradient of $4-20$ psu (practical salinity units) was measured during high tides at the internal-most stations (Fig. 10a). Vegetative cells of $K$. foliaceum were present in high concentrations, coinciding with the front (Fig. 10b), but concentrations as high as $15 \times 10^{4}$ cells $^{-1}$ were detected during falling tides, with salinities of $19-24$ psu during ebb tides.

Culture maintenance and growth: Three strains, Baiona A3, Baiona B1, and Baiona B9, were employed in this study. All three derived from single cells and therefore were clonal. These cultures were deposited in the culture collection of the Spanish Institute of Oceanography in Vigo (Contact address: Instituto Español de Oceanografía, Centro Oceanográfico de Vigo, Subida á Radio Faro, 50, E36390 Vigo, Spain, http:// www.vi.ieo.es). The cultures were grown at $19{ }^{\circ} \mathrm{C}$ with a photoperiod of $12: 12 \mathrm{~h}$ light:dark (L:D) cycle. Illumination was achieved with fluorescence tubes, which provided a photon irradiance of $90 \mu \mathrm{mol}$ photons $\mathrm{m}^{-2} \mathrm{~s}^{-1}$. Culture stocks were maintained in Erlenmeyer flasks filled with $50 \mathrm{ml}$ of $\mathrm{L} 1$ medium (Guillard and Hargraves 1993), without the addition of silica, prepared with Atlantic seawater and adjusted to a salinity of $10 \mathrm{psu}$ by the addition of sterile Milli-Q water. Duplicate Erlenmeyer flasks were filled with $50 \mathrm{ml}$ of $\mathrm{L} 1$ medium, inoculated with 200 cells of each parental strain $\mathrm{ml}^{-1}$, and sampled every 2 days. Strain Baiona B9 was cultured at three different temperatures $\left(15,19\right.$, and $\left.24^{\circ} \mathrm{C}\right)$ and adapted at each temperature over a period of 1 month. Subsamples were fixed with Lugol's solution for cell enumeration in Sedwick-Rafter chambers; at least 200 cells were counted.

Morphology of the vegetative stage: Morphology was assessed in live or formalin-fixed cultured cells. The plate pattern was identified by staining the cells with Fluorescent Brightener 28 (Sigma, St. Louis, MO, USA) following a modification of the technique reported by Fritz and Triemer (1985).

Size of vegetative stages: The cells were counted and their sizes measured with a Multisizer 3 Coulter counter (Beckman) and by using a $63 \times$ lens mounted on an inverted microscope (Axiovert Zeiss 135, Oberkochen, Germany).

Planozygote behavior: Strain Baiona B9 was self-crossed at $19^{\circ} \mathrm{C}$ in $10 \mathrm{ml}$ of medium without added nitrates $(L-N)$. Duplicate sterile polystyrene Petri dishes (35-mm diameter, Iwaki, Tokio, Japan) were inoculated with exponentially 

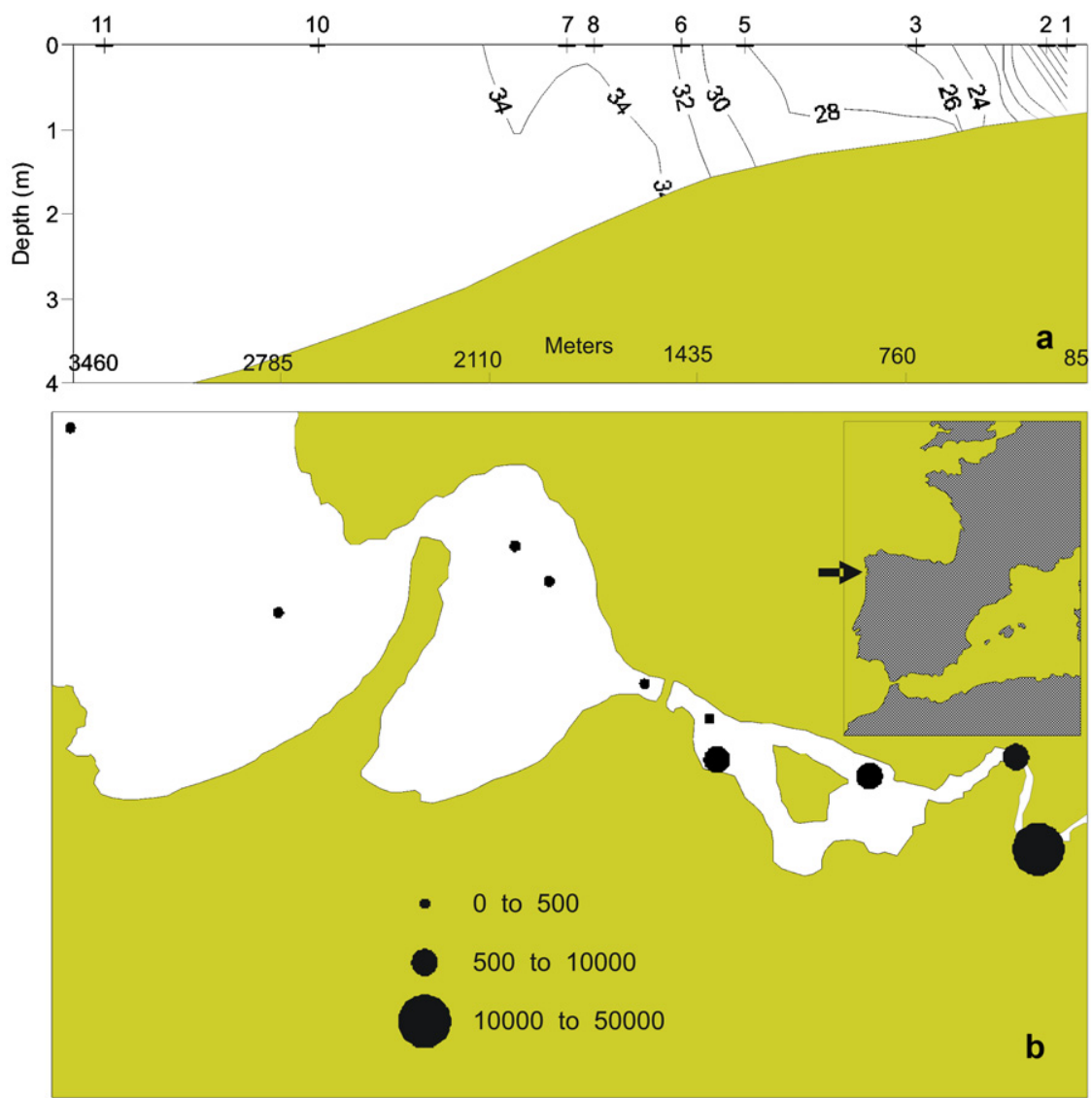

Figure 10. Vertical salinity gradient (a) and cell concentration (cells $\left.I^{-1}\right)(\mathbf{b})$ in the study area.

growing cells $\left(3000-5000\right.$ cells $\left.\mathrm{ml}^{-1}\right)$ to a final concentration of 700 cells $\mathrm{ml}^{-1}$. Thirty planozygotes were individually isolated and separately transferred to 96-well tissue culture plates (Iwaki, Tokio, Japan) filled with $0.4 \mathrm{ml}$ of L1 medium at $10 \mathrm{psu}$. These cultures were placed under the same conditions as those previously described for culture maintenance. Planozygote evolution was monitored at least daily and photographically documented with a digital camera (CANON EOS-D60, Tokio, Japan). The size of these cells was determined using a $63 \times$ lens mounted on an inverted microscope (Axiovert Zeiss 135, Oberkochen, Germany) and a black and white analogical video camera (Sony AVC-D5CE; Sony Co., Tokyo, Japan) mounted on the microscope together with a camera adapter and an Image IPplus analyzer (Media cybernetics, Berkshire, UK).

Staining of sexual-stage nuclei: Sexual stages in different phases of development $(n \geqslant 5)$ were stained in order to visualize their nuclei. Fusing gamete pairs, planozygotes, cysts, and germlings from the self-cross of strain Baiona B9 in $\mathrm{L}-\mathrm{N}$ medium were individually isolated and fixed for $10-15 \mathrm{~min}$ in $2 \%$ paraformaldehyde in $0.01 \mathrm{M}$ PBS (phosphate-buffered saline, Sigma, St. Louis, USA), pH7.4. The fixed cells were washed in several drops of PBS buffer and then stained with 1:100 Sybr green (Molecular Probes, Eugene Oregon, USA) in $0.01 \mathrm{M}$ PBS, pH7.4, for $30 \mathrm{~min}$, washed again, and observed by fluorescence microscopy (LEICA DMLA, Wetzlar, Germany) with excitation filters of BP $450-490 \mathrm{~nm}$ and a long-pass emission filter (LP 515).
Dormancy period and excystment of wild and culture cysts: Thirty wild and 30 newly formed culture cysts were individually isolated into 96-well sterile polystyrene plates (Iwaki, $6.4 \mathrm{~mm}$ diameter) and checked for excystment every 2 days. Excystment was defined as the complete emergence of the protoplast from the cyst even if the germling remained non-motile (Anderson and Wall 1978). From the cysts isolated on a given date, the percentage that had germinated was determined by dividing the number of germinated cysts by the number of non-germinated ones. The development of the germinated cells (planomeiocytes) was assessed at least daily and they were photographed as explained above.

Diel division cycle (synchronization experiment): To study the cell cycle in $K$. foliaceum, the clonal strain Baiona B9 was incubated in duplicate at a density of $5000-5500$ cells $\mathrm{ml}^{-1}$ in replete $\mathrm{L} 1$ medium in 0.5 -I Erlenmeyer bottles. At this cell density (exponential growth phase) and after the completion of a 24-h 12L:12D cycle, the incubators lights were turned off for a period of $48 \mathrm{~h}$ during which the cultures were synchronized by maintaining them in darkness. After the light conditions had been restored, duplicate samples for cell counting and flow cytometric analysis were taken every $2 \mathrm{~h}$ during $24 \mathrm{~h}$.

Study of the dinoflagellate and endosymbiont cell cycle by flow cytometry: DNA analyses were done following the method described by Figueroa et al. (2006, 2007). Culture aliquots of $45 \mathrm{ml}$ were fixed in $1 \%$ paraformaldehyde for $10 \mathrm{~min}$ at room temperature and washed with PBS 
(Sigma-Aldrich, USA, \#P4417), $\mathrm{pH}$ 7. After centrifugation (4500 rpm, $20 \mathrm{~min}$ ), chlorophyll was extracted by resuspending the pellet in $3 \mathrm{ml}$ cold methanol and storing the suspension for $12 \mathrm{~h}$ at $4{ }^{\circ} \mathrm{C}$. The cells were washed twice in PBS and resuspended in staining solution (PBS, $3 \mu \mathrm{g}$ propidium

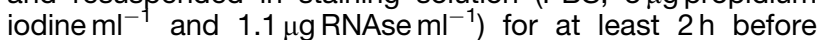
analysis with a Becton Dickinson FACScalibur bench machine with a laser emitting at $488 \mathrm{~nm}$. Samples were run at low flux (approx. $18 \mu \mathrm{min}^{-1}$ ) and data were acquired in linear and log modes until around 10000 events had been recorded. The internal standard consisted of a solution containing $10^{6}$ particles $\mathrm{ml}^{-1}$ of yellow-green $0.92-\mu \mathrm{m}$ Polysciences latex beads, with $10 \mu \mathrm{l}$ added per sample. Fluorescence emission of propidium iodide was detected at $617 \mathrm{~nm}$. ModFit LT (Verity software House, Topsham, ME, USA) was used to determine the distribution of the DNA fluorescence of the population, computing the peaks, their ratios, and the coefficients of variation (CVs). To compare the trends of the different treatments with respect to cell-cycle pattern, the percentages of cells in the G1, S, and G2/M phases were adjusted to yield polynomial curves and the delimited areas were integrated over the diel cycle.

\section{Acknowledgements}

This research was funded by the EU Project SEED (GOCE-CT-2005-003875). RI Figueroa's work is supported by a I3P contract, E Garcés work by a Ramon y Cajal grant and G Llaveria held an FPU fellowship, all from the Spanish Ministry of Innovation and Science. We thank JM Fortuño, A Fernández-Villamarín, and I Ramilo for technical assistance.

\section{References}

Anderson DM (1980) Effects of temperature conditioning on development and germination of Gonyaulax tamarensis (Dinophyceae) hypnozygotes. J Phycol 16: 166-172

Anderson DM (1997) Bloom dynamics of toxic Alexandrium species in the northeastern US. Limnol Oceanogr 42: 1009-1022

Anderson DM, Rengefors K (2006) Community assembly and seasonal succession of marine dinoflagellates in a temperate estuary - the importance of life cycle events. Limnol Oceanogr 51: 860-873

Anderson DM, Wall D (1978) Potential importance of benthic cysts of Gonyaulax tamarensis and G. excavata in initiating toxic dinoflagellate blooms. J Phycol 14: 224-234

Anderson DM, Kulis DM, Binder BJ (1984) Sexuality and cyst formation in the dinoflagellate Gonyaulax tamarensis: cyst yield in bath cultures. J Phycol 20: 418-425

Bell G (1982) The Masterpiece of Nature: The Evolution and Genetics of Sexuality. Croom Helm, London; University of California Press, Berkeley
Bernstein H (1983) Recombinational repair may be an important function of sexual reproduction. BioScience 33: $326-331$

Bhattacharya D, Archibald JM, Weber APM, Reyes-Prieto A (2007) How do endosymbionts become organelles? Understanding early events in plastid evolution. BioEssays 29: $1239-1246$

Biecheler B (1952) Reserches sur les Péridiniens. Bull Biol Fr Belg Supplément 36: 1-149

Blanchard-Babillot C (1972) Recherches sur le mode de division du peridinien Glenodinium foliaceum. C R Acad Sci Paris 275: 2635-2637

Bodył A, Moszczyński K (2006) Did the peridinin plastid evolve through tertiary endosymbiosis? A hypothesis. Eur J Phycol 41: 435-448

Bravo I, Anderson DM (1994) The effects of temperature, growth medium and darkness on excystment and growth of the toxic dinoflagellate Gymnodinium catenatum from northwest Spain. J Plankton Res 16: 513-525

Bruggeman J, Debets AJM, Wijngaarden PJ, Arjan J, deVisser GM, Hoekstra RF (2003) Sex slows down the accumulation of deleterious mutations in the homothallic fungus Aspergillus nidulans. Genetics 164: 479-485

Chesnick JM, Cox ER (1987) Synchronized sexuality of an algal symbiont and its dinoflagellate host, Peridinium balticum (Levander) Lemmermann. BioSystems 21: 69-78

Chesnick JM, Cox ER (1989) Fertilisation and zygote development in the binucleate dinoflagellate Peridinium balticum (Pyrrophyta). Am J Bot 76: 1060-1072

Chesnick JM, Morden CW, Shmieg AM (1996) Identity of the endosymbiont of Peridinium foliaceum (Pyrroophyta): analysis of the rbcLS operon. J Phycol 26: 741-751

Chesnick JM, Kooistra WH, Wellbrock U, Medlin LK (1997) Ribosomal RNA analysis indicates a benthic pennate diatom ancestry for the endosymbionts of the dinoflagellates Peridinium foliaceum and Peridinium balticum. J Eukaryot Microbiol 44: $314-320$

Dale B, Yentsch CM, Hurst JW (1978) Toxicity in resting cysts of the red tide dinoflagellate Gonyaulax excavata from deeper water coastal sediments. Science 201: 1223-1225

Dodge JD, Crawford RM (1969) Observations on the fine structure of the eyespot and associated organelles in the dinoflagellate Glenodinium foliaceum. J Cell Sci 5: 479-493

Falkowski PG, Katz ME, Knoll AH, Quigg A, Raven JA, Schofield O, Taylor FJR (2004) The evolution of modern eukaryotic phytoplankton. Science 305: 354-360

Figueroa RI, Bravo I, Garcés E (2006) The multiple routes of sexuality in Alexandrium taylori (Dinophyceae) in culture. J Phycol 42: 1028-1039

Figueroa RI, Garcés E, Bravo I (2007) Comparative study between the life cycles of Alexandrium tamutum and Alexandrium minutum (Gonyaulacales, Dinophyceae) in culture. J Phycol 43: 1039-1053

Fritz L, Triemer RE (1985) A rapid simple technique utilizing calcofluor white M2R for the visualization of dinoflagellate thecal plates. J Phycol 21: 662-664 
Guillard RRL, Hargraves PE (1993) Stichochrysis immobilis is a diatom, not a chrysophyte. Phycologia 32: 234-236

Hackett JD, Yoon HS, Soares MB, Bonaldo MF, Casavant TL, Scheetz TE, Nosenko T, Bhattacharya D (2004) Migration of the plastid genome to the nucleus in a peridinin dinoflagellate. Curr Biol 13: 213-218

Hallegraeff GM, Marshall JA, Valentine J, Hardiman S (1998) Short cyst-dormancy period of an Australian isolate of the toxic dinoflagellate Alexandrium catenella. Mar Freshwater Res 49: 415-420

Hamilton WD (1980) Sex versus non-sex versus parasite. Oikos 35: 282-290

Horiguchi T, Pienaar RN (1994) Ultrastructure of a new marine sand-dwelling dinoflagellate, Gymnodinium quadrilobatum sp. nov. (Dinophyceae) with special reference to its endosymbiotic alga. Eur J Phycol 29: 237-245

Horiguchi T, Takano Y (2006) Serial replacement of a diatom endosymbiont in the marine dinoflagellate, Peridinium quinquecorne (Peridiniales, Dinophyceae). Phycol Res 54: $193-200$

Imanian B, Keeling PJ (2007) The dinoflagellates Durinskia baltica and Kryptoperidinium foliaceum retain functionally overlapping mitochondria from two evolutionarily distinct lineages. BMC Evol Biol 7: 172

Imanian B, Carpenter KJ, Keeling PJ (2007) The mitochondrial genome of a tertiary endosymbiont retains genes for electron transport proteins. J Eukaryot Microbiol 54: 146-153

Ishida K, Green BR (2002) Second- and third-hand chloroplasts in dinoflagellates: phylogeny of oxygen-evolving enhancer 1 (PsbO) protein reveals replacement of a nuclear-encoded plastid gene by that of a haptophyte tertiary endosymbiont. Proc Natl Acad Sci USA 99: 9294-9299

Kempton JW, Wolny J, Tengs T, Rizzo P, Morris R, Tunnell J, Scott P, Steidinger K, Hymel SN, Lewitus AJ (2002) Kryptoperidinium foliaceum blooms in South Carolina: a multianalytical approach to identification. Harmful Algae 1: $383-392$

Kite GC, Rothschild LJ, Dodge JD (1988) Nuclear and plastid DNAs from the binucleate dinoflagellates Glenodinium (Peridinium) foliaceum and Peridinium balticum. Biosystems 21: $151-163$

Koike K, Sekiguchi H, Kobiyama A, Takishita K, Kawachi M, Koike K, Ogata T (2005) A novel type of kleptoplastidy in Dinophysis (Dinophyceae): presence of haptophyte-type plastid in Dinophysis mitra. Protist 156: 225-237

Lebour M (1925) The Dinoflagellates of Northern Seas. Marine Biological Association of the United Kingdom, Plymouth

Lewis Jr. WM (1984) The diatom sex clock and its evolutionary significance. Am Nat 123: 73-80

Lindemann E (1924) Der Bau der Hülle bei Heterocapsa und Kryptoperidinium (Stein) n. nov. (zugleich eine vorl. Mitteilung). Bot Arch 5: 114-120

Lively CM (1989) Adaptation by a parasitic trematode to local populations of its snail host. Evolution 43: 1663-1671
Lubchenco J, Cubit J (1980) Heteromorphic life histories of certain marine algae as adaptations to variations in herbivory. Ecology 61: 676-686

Margulis L (1970) Origin of Eukaryotic Cells. Yale University Press, New Haven

Martin M, Kowallik KV (1999) Annotated English translation of Mereschowsky's 1905 paper 'Über Natur und Ursprung der Chromatophoren im Pflanzenreiche'. Eur J Phycol 34: 287-295

Minnhagen S, Janson S (2006) Genetic analyses of Dinophysis spp support kleptoplastidy. FEMS Microbiol Ecol 57: $47-54$

Montresor M, Marino D (1996) Modulating effect of cold-dark storage on excystment in Alexandrium pseudogonyaulax (Dinophyceae). Mar Biol 127: 55-60

Otto SP (2003) The advantages of segregation and the evolution of sex. Genetics 164: 1099-1118

Patron NJ, Waller RF, Keeling PJ (2006) A tertiary plastid uses genes from two endosymbionts. J Mol Biol 357: $1373-1382$

Pérez CC, Roy S, Anderson DM (1998) Control of germination of Alexandrium tamarense (Dinophyceae) cysts from the lower St. Lawerence estuary (Canada). J Phycol 34: 242-249

Pfiester LA (1977) Sexual reproduction of Peridinium gatunense (Dinophyceae). J Phycol 13: 92-95

Pienaar RN, Sakai H, Horiguchi T (2007) Description of a new dinoflagellate with a diatom endosymbiont, Durinskia capensis sp. nov. (Peridiniales, Dinophyceae) from South Africa. J Plant Res 120: 247-258

Rengefors K, Anderson DM (1998) Environmental and endogenous regulation of cyst germination in two fresh-water dinoflagellates. J Phycol 34: 568-577

Richerd S, Couvet D, Valéro M (1993) Evolution of the alternation of haploid and diploid phases in life cycles. II. Maintenance of the haplo-diplontic cycle. J Evol Biol 6: $263-280$

Rizzo PJ (1991) The enigma of the dinoflagellate chromosome. J Protozool 38: 246-252

Stebbins GL, Hill GJC (1980) Did multicellular plants invade the land? Am Nat 115: 342-353

Steidinger K, Garcés E (2006) Life Cycles of Harmful Algae: an Overview. In Graneli E, Turner JT (eds) Ecology of Harmful Algae. Springer, Heidelberg, pp 37-49

Takishita K, Koike K, Maruyama T, Ogata T (2002) Molecular evidence for plastid robbery (kleptoplastidy) in Dinophysis, a dinoflagellate causing diarrheic shellfish poisoning. Protist 153: 293-302

Tamura M, Shimada S, Horiguchi T (2005) Galeidiniium rugatum gen. et $\mathrm{sp}$. nov. (Dinophyceae), a new coccoid dinoflagellate with a diatom endosymbiont. J Phycol 41: 658-671

Tippit DH, Pickett-Heaps JD (1976) Apparent amitosis in the binucleate dinoflagellate Peridinium balticum. J Cell Sci 21: $273-289$ 
Trigueros JM, Orive E (2000) Tidally driven distribution of phytoplankton blooms in a shallow, macrotidal estuary. J Plankton Res 22: 969-986

Walker LM, Steidinger KA (1979) Sexual reproduction in the toxic dinoflagellate Gonyaulax monilata. J Phycol 15: 312-315

Wall D (1971) Biological problems concerning fossilizable dinoflagellates. Geosci Man 3: 1-15

Watanabe MM, Suda S, Inouye I, Sawaguchi T, Chihara M (1990) Lepidodinium viride gen. et sp. nov. (Gymnodiniales, Dinophyta), a green dinoflagellate with a chlorophyll $a-$ and $b$ containing endosymbiont. J Phycol 26: 741-751

Wolny JL, Kempton JW, Lewitus AJ (2004) Taxonomic Reevaluation of a South Carolina "Red Tide" Dinoflagellate
Indicates Placement in the Genus Kryptoperidinium. In Steidinger KA, Landsberg JH, Tomas CR, Vargo GA (eds) Harmful Algae 2002, Florida Fish and Wildlife Conservation Commission. Florida Institute of Oceanography and Intergovernmental Oceanographic Commission of UNESCO, pp 443-445

Yoon HS, Hackett JD, Bhattacharya D (2002) A single origin of the peridinin and fucoxanthin containing plastids in dinoflagellates through tertiary endosymbiosis. Proc Natl Acad Sci USA 99: 11724-11729

Yoon HS, Hackett JD, Van Dolah FM, Nosenko T, Lidie KL, Bhattacharya D (2005) Tertiary endosymbiosis driven genome evolution in dinoflagellate algae. Mol Biol Evol 22: 1299-1308

Available online at www.sciencedirect.com

\section{ScienceDirect}

